\title{
Extrahepatic Bile Duct Mucinous Adenocarcinoma
}

National Cancer Institute

\section{Source}

National Cancer Institute. Extrahepatic Bile Duct Mucinous Adenocarcinoma. NCl

Thesaurus. Code C5846.

An adenocarcinoma that arises from the extrahepatic bile ducts. It is characterized by the presence of extracellular mucin that constitutes more than fifty-percent of the tumor. 